https://doi.org/10.30843/nzpp.2018.71.216

\title{
Velvetleaf regenerates and reproduces after cropping
}

\author{
Claire A. Dowsett* and Trevor K. James \\ ${ }^{1}$ AgResearch, Ruakura Research Centre, Private Bag 3123, Hamilton 3240, New Zealand \\ *Corresponding author: Claire.dowsett@agresearch.co.nz
}

Velvetleaf (Abutilon theophrasti) was accidentally introduced into New Zealand in 2016 and intensive efforts are being implemented to mitigate the risk of its naturalisation. This study investigated the possibility of velvetleaf plants surviving in maize fields following silage harvest in late summer and early autumn. Velvetleaf plants were grown to maturity in a glasshouse during the summer of 2017-2018. They were left to seed and senesce naturally and, on 28 February 2018, five senesced plants were "harvested" at each height $(0,30,50,70$ and $150 \mathrm{~mm})$ with varying numbers of leaf nodes remaining $(0,0,1,2$ and 3 pairs respectively). Velvetleaf was capable of regeneration 2-4 weeks after "harvest" from these leaf nodes. Forty percent regeneration occurred with 1 pair of nodes; $80 \%$ (2 pairs); and $100 \%$ ( 3 pairs). All regenerated plants subsequently produced mature seed pods with viable seed (95\% germination) 6-10 weeks following "harvest". Maize silage crops are normally cut $\sim 100 \mathrm{~mm}$ above ground level. In this study, velvetleaf was able to regenerate and reproduce following simulated maize silage harvest at, below and above, normal cutting height. Growers are advised to continue management strategies for velvetleaf to prevent seed set following maize silage harvest and before sowing of the next crop or pasture.

https://doi.org/10.30843/nzpp.2018.71.217

\section{Local adaptation in a New Zealand invader, Mimulus guttatus?}

\author{
Michelle E. Williamson ${ }^{1, \star}$, Philip E. Hulme ${ }^{2}$, Dave A. Conder ${ }^{1}$ and Hazel M. Chapman ${ }^{1}$ \\ ${ }^{1}$ University of Canterbury, Private Bag 4800, Christchurch 8140, New Zealand \\ ${ }^{2}$ Lincoln University, PO Box 85084, Lincoln 7647, New Zealand \\ Corresponding author: michelle@williamsonz.co.nz
}

The New Zealand flora comprises proportionately more alien species than anywhere else on Earth. Many of these species are 'sleeper' species, currently not invasive but with the potential to become so. Understanding what traits lead to sleepers becoming invasive is a key question in invasion biology. One hypothesis is local adaptation - that is, selection pressures in an alien habitat select for certain genetic traits favouring species spread. In New Zealand, the semi-aquatic herb Mimulus gutattus, 'monkey flower', is already showing signs of becoming invasive and is widespread across the South Island, blocking waterways and ditches. A common garden experiment was used to test for local adaptation in 37 populations of monkey flower from 8 regions across the North and South Islands of New Zealand. Possible adaptations in plant physiology (including, fresh vs dry weight, flower size, and photosynthetic rate) were examined. Observable differences include significant differences in biomass and leaf morphology. Results to date indicate significant genetic differences among New Zealand monkey flower populations. This is indicative of invasive potential. 